\title{
Os vendedores de verdades: o dizer verdadeiro e a sedução negacionista na cena pública como problema para o jornalismo e a história (2010-2020) ${ }^{1}$
}

The Truth Sellers: Truth-Telling and Denialist Seduction in the Public Scene as a Problem for Journalism and History (2010-2020)

Sônia Meneses*

\section{Resumo}

Este artigo analisa a emergência da nova onda negacionista na década de 2010 partindo de uma reflexão sobre modelos de veridicção dispostos na cena pública contemporânea. Argumenta que vivemos uma crise desses modelos tradicionais que se estabeleceram como uma tecnologia da verdade, denominada por Michel de Foucault "verdade conhecimento", ou verdade demonstrativa. Para isso, explicita o que são os modos de veridicção apresentados pelo autor e como eles produzem regimes de verdade. Procura apresentar o jornalismo e a história em seus modos de dizer-verdadeiro, e como eles têm sido impactados pelos efeitos da negação. Ao final, toma como exemplo de sintoma desse processo a negação da ditadura militar brasileira. Palavras-chave: Negacionismo; Verdade; História.

\section{Abstract}

This article analyzes the emergence of the new wave of negationism in the 2010s, starting from a reflection on models of veridiction in the contemporary public scene. It argues that we live in a crisis of these traditional models that were established as a technology of truth, called by Michel de Foucault "knowledge truth" or demonstrative truth. To this end, it explains what the modes of veridiction presented by the author are and how they produce regimes of truth. It seeks to present journalism and history in their modes of truth-telling, and how they have been impacted by the effects of negation. In the end, it takes as an example of a symptom of this process the denial of the Brazilian military dictatorship. Keywords: Denial; Truth; History.

\footnotetext{
* Universidade Regional do Cariri (URCA), Crato, CE, Brasil. sonia.meneses@urca.br <https://orcid. org/0000-0001-5099-0530>
} 
O governo de Jair Bolsonaro enviou telegrama à ONU (Organização das Nações Unidas) afirmando que "não houve golpe de Estado" em 31 de março de 1964 e que os 21 anos de governos militares foram necessários "para afastar a crescente ameaça de uma tomada comunista do Brasil e garantir a preservação das instituições nacionais, no contexto da Guerra Fria” (Senra, 2019, grifamos).

Passados 35 anos do encerramento do último ciclo ditatorial brasileiro, em 2020, foi a primeira vez que um governo negou oficialmente a ditadura militar (1964-1985). O telegrama encaminhado à ONU nas efemérides do episódio, em 2019, seria impensável, especialmente vindo de um governo eleito sob o manto democrático. Contudo, não estamos falando de qualquer governante. Além disso, sua postura sobre a ditadura é bastante conhecida. O político Jair Bolsonaro, ao longo de seus quase 30 anos dedicados ao legislativo, construiu uma longa trajetória de apologia à ditadura militar. Segundo o jornal O Estado de São Paulo, o então deputado mencionou o episódio, ou assuntos relacionados a ele, em 1/4 de seus discursos (Menegat, 2019).

Além de afirmar que "não houve golpe de estado", no telegrama encontramos as grandes linhas argumentativas que justificaram o Golpe a partir de seus apoiadores, a exemplo do recurso ao perigo comunista. Rodrigo Patto Sá Motta (2002) nos demonstrou como o discurso anticomunista se tornou um poderoso elemento de mobilização política e, já em 1964, “a estratégia era a mesma há décadas: passar para a sociedade uma impressão aterrorizante dos comunistas, no intuito de levantar contra eles a indignação popular" (Motta, 2002, p. 339).

O desprezo pelas evidências, pelos testemunhos das vítimas, pelas ações judiciais, e as tentativas recorrentes de deslegitimação da historiografia profissional, implícitos no telegrama, fazem parte de um repertório amplo da negação que tem sido, há alguns anos, mobilizado em nosso cotidiano, embora não tenha sido enfrentado enquanto tal. Portanto, cabe-nos perguntar já de partida: por que demoramos tanto tempo para definir/assumir essas posturas como investimentos negacionistas em nossa sociedade?

Em parte, talvez possamos adiantar, concordando com Roberto Vecchi e Regina Dalcastagnè (2014), que "há uma guerra de nomes ainda não resolvida - e de resultado ainda imprevisível” em nosso país, e, não nomear essas ações 
por aquilo que elas são, muitas vezes pode ser um sintoma da dificuldade de enfrentarmos nosso passado, mas também, de um tipo de negação. Exatamente devido a isso, as falas negacionistas do então deputado, e hoje presidente da República, passaram como pilhéria, bravata, ditos de pouca importância.

Percebe-se que a problemática do negacionismo ganhou uma força até então inédita no Brasil, e tem atingido grupos cada vez mais receptivos a tais argumentos. Todavia, a negação de acontecimentos históricos e informações não é um problema apenas para o Brasil; parecendo um fenômeno que se espraia em diversas sociedades.

É preciso ressaltar que, na cena pública brasileira, nos deparamos com ataques a uma grande variedade de temas históricos, ecológicos e científicos. $\mathrm{Na}$ história, observamos questões relacionadas à escravidão, ao extermínio indígena, ou mesmo a personagens históricos - que têm sido retirados de documentos oficiais e de instituições cujas funções principais são o trabalho de salvaguarda do passado ${ }^{2}$, sendo objetos constantes da negação.

Neste artigo, tentarei desenhar algumas possíveis explicações para o fenômeno da negação na cena pública, partindo de um movimento inverso: em lugar de me questionar sobre a negação, começarei interrogando sobre as ideias de verdade, ou sobre os modos de veridicção, a partir das proposições apontadas por Foucault $(2012,2017,2018)$.

Argumento que, para compreendermos a movimentação negacionista em nosso tempo, antes é necessário nos perguntarmos sobre as tecnologias e os posicionamentos da verdade que operamos em nossa sociedade, e como a própria disciplina histórica tem sido atacada, numa possível erosão em seu modelo de veridicção. Não tratarei de uma história da verdade, mas de como houve um arranjo sobre modos de veridicção que gestaram, em nossa sociedade, um determinado regime de verdade ainda em vigor entre nós. Nesse universo, a própria ideia de verdade se tornou um produto/mercadoria vendido como informação. Na sequência, retomarei o debate acerca da ditadura militar.

\section{UMA CRISE DA VERDADE "VERDADEIRA"? - SOBRE MODOS DE VERIDICÇÃO E REGIMES DE VERDADE}

Em agosto de 2011, Wiliam Bonner e Fátima Bernardes, âncoras do Jornal Nacional, apresentavam ao grande público os princípios editoriais do grupo 
Globo. Uma matéria incomum para um jornal televisivo, pois trazia aos telespectadores os elementos conceituais e protocolares do jornalismo "profissional".

Wiliam Bonner: as organizações Globo divulgaram hoje um documento com os princípios editoriais em vigor nos seus produtos jornalísticos [...].

Fátima Bernardes: Na carta, os acionistas afirmam que, com a possibilidade muito positiva de todos os indivíduos publicarem suas ideias e opiniões na internet, instaurou-se uma certa confusão sobre o que é ou não jornalismo. Eles dizem que, por esse motivo, é preciso tornar claro os princípios editoriais das empresas que se dedicam a fazer jornalismo profissionalmente e explicam que "o objetivo não é somente diferenciar-se, mas facilitar o julgamento do público sobre o trabalho dos veículos, permitindo, de forma transparente, que qualquer um verifique se a prática é condizente com a crença”.

Wiliam Bonner: o documento apresenta a definição de jornalismo adotado pelo grupo, [...] pode-se dizer que jornalismo é "o conjunto de atividades que, seguindo certas regras e princípios, produz um primeiro conhecimento sobre fatos e pessoas". (Organizações Globo divulgam..., 2011, grifamos).

Na exposição, se percebe, logo de partida, uma ação de distinção entre o que seria uma prática jornalística legítima, pois "profissional" dos meios, de uma "positiva", mas não profissional, da exposição de opiniões e ideias de leitores na internet. A carta é categórica: é o jornalismo "profissional" que deve oferecer o primeiro "conhecimento sobre fatos e pessoas", porque ele tem os elementos protocolares para a mediação do real. Balizados por esse saber que organiza e distribui a verdade, é possível aos leitores, telespectadores e internautas finalmente escolherem seus caminhos e realizarem julgamentos.

A apresentação da carta editorial reflete preocupações bastante significativas para o poderoso grupo de mídia, como a expansão de conteúdos advindos da internet não apenas no Brasil, mas no mundo. Àquela altura, em 2011, a circulação e a produção de informação já haviam se transformado definitivamente, com a consolidação das redes de compartilhamento. Em 2016, houve a virada decisiva, quando o acesso às notícias deixou de se concentrar nos grandes portais dos jornais e passou a ocorrer, majoritariamente, por redes de compartilhamento pessoais como o Facebook, o WhatsApp, o Twitter e o Instagram.

Segundo dados do relatório anual produzido pelo Reuters Institute em 
2017, menos da metade da população dos 36 países pesquisados naquele ano acreditava nas informações das mídias tradicionais. No Brasil, o percentual de confiança ainda era alto comparado aos demais países, com $60 \%$ de confiança nos meios (Reuters Institute, 2017, p. 106). Em 2019, esse percentual despenca para apenas $48 \%$ de pessoas que afirmavam acreditar em notícias que circulavam nas mídias tradicionais (Reuters Institute, 2019). Tais dados representam o processo de mudança, tanto em relação à distribuição e à produção da informação quanto no posicionamento da verdade relacionado a ela. A carta editorial do grupo Globo é a defesa de um dado modo de operar a verdade, um tipo específico de saber, mas é também a tentativa de manutenção de uma relação de poder entre o grupo e seus leitores.

Para entendermos o que significa o dizer-a-verdade para o jornalismo, mas também para a história, parto das questões postuladas por Foucault (2012, 2017) para propor uma reflexão sobre o posicionamento da verdade a partir da compreensão acerca dos modos de veridicção que a sustentam.

Em suas últimas aulas, já no ano de 1984, Foucault nos apresenta um conjunto de reflexões sobre o posicionamento da verdade, que me parece fundamental para compreendermos aspectos desse momento em que vivemos. Segundo o autor, seu desafio, em sua extensa trajetória intelectual, foi compreender como se articulam seus temas fundamentais, quais sejam: a verdade, o poder e o sujeito. Naquele momento, o filósofo propunha um deslocamento que marcava, talvez, o último ponto de inflexão em sua obra:

Trata-se [...] da análise de relações complementares entre três elementos distintos, que não se reduzem uns aos outros, que não se absorvem uns aos outros, mas cujas relações são constitutivas umas às outras. Esses três elementos são: os saberes, estudados na especificidade da sua veridicção; as relações de poder, estudadas não como uma emanação de um poder substancial, invasivo, mas nos procedimentos pelos quais a conduta dos homens é governada; e enfim, os modos de constituição dos sujeitos através das práticas de si. É realizando esse tríplice deslocamento teórico - do tema do conhecimento, para o tema da veridicção, do tema da dominação para o tema da governamentalidade, do tema do indivíduo para o tema das práticas de si - que se pode, assim me parece, estudar as relações entre verdade, poder e sujeito [...] (Foucault, 2017, p. 10).

Dedicando-se ao tema da verdade, mais especificamente às práticas de dizer-a-verdade, ou aos modos de veridicção, o autor sugere a existência de 
quatro modelos que, a partir da Antiguidade, têm predominado e, de alguma forma, mobilizado a ordenação de diferentes regimes de verdade. Foucault dá destaque ao modelo parresiasta, tema recorrente em diversos textos. Diz o autor: "a parresía ${ }^{3}$ em vez de uma técnica à maneira da retórica, deve ser caracterizada como uma modalidade do dizer-a-verdade" (Foucault, 2017, p. 15). Tal modelo de veridicção é, para ele, um ponto basilar, porque diz respeito ao dizer verdadeiro para si, aspecto constitutivo do próprio processo de reconhecimento e aceitação da verdade pelo sujeito.

Mas, dizer a verdade para si, a fala franca, que caracteriza a parresía, pode ter duas distinções. Na primeira, ser "o tipo de ato pelo qual o sujeito dizendo a verdade [...] representa a si e é reconhecido pelos outros como dizendo a verdade" (Foucault, 2017, p. 4). O autor menciona "algumas formas culturalmente reconhecidas e típicas" dessa modalidade, a exemplo da confissão, do exame de consciência, etc. É o sujeito quem fala para si mesmo sua verdade.

Foucault vai além, e afirma: "foi estudando essas práticas de si [...] que vi se delinear, de um certo modo, um personagem" (Foucault, 2017, pp. 6-7). Esse personagem é um outro indispensável, segundo o autor. O sujeito que estabelece com seu interlocutor uma relação de confiança, pois lhe permite dizer a verdade sobre ele, mesmo que tal verdade nem sempre seja bem-vinda. Esse outro, que exerce a função parresiástica, coloca-se sempre em risco, perante seu interlocutor.

O parresiasta exerce uma função política, pois está autorizado a dizer a verdade, seja ela qual for. Assim, o modo de veridicção parresiasta pressupõe um jogo: "para que haja parresía, é preciso que, no ato da verdade, haja primeiro a manifestação de um vínculo fundamental entre a verdade dita e o pensamento de quem disse" (Foucault, 2017, p. 14), e dizer a verdade implica em risco, pois nem sempre a verdade dita é desejada, por isso, uma das características da parresía é justamente a coragem da verdade:

Aquele a quem a verdade é dita - quer se trate de um povo reunido e que delibera sobre as melhores decisões a tomar, quer se trate do Príncipe, do tirano ou do rei a que é preciso dar conselhos, quer se trate do amigo que você guia [...] se quiser desempenhar o papel que lhe propõe parresiasta dizendo-lhe a verdade [deve] aceitá-la, por mais desagradáveis que sejam para as opiniões estabelecidas" (Foucault, 2017, p. 13). 
Detive-me um pouco mais na apresentação desse conceito por considerá-lo importante na reflexão que desenvolvo aqui, pois esse é o modelo de veridicção que "põe em jogo o discurso verdadeiro do que os gregos chamavam de éthos" (Foucault, 2017, p. 25). Por isso, é, sobretudo, político, pois intimamente relacionado a um posicionamento ético. Será em relação a ele que o autor apresentará os demais modos de dizer verdadeiros: o modo de dizer-a-verdade da profecia/profeta, o dizer-a-verdade da sabedoria/sábio e o modelo da técnica/instrutor/professor.

O modo de veridicção profético é aquele cuja verdade se relaciona diretamente com o futuro, uma verdade a ser revelada, algo que foi recebido de um outro. O profeta não fala em seu nome, "endereça aos homens uma verdade que vem de outro lugar” (Foucault, 2017, p. 15). É a verdade que se assenta numa ideia de destino. O segundo modelo é o modo de veridicção da sabedoria, aquela que emana do sábio, formulada como valor de prescrição, e não conselho dirigido a outrem. É o domínio do ser: "no fundo, o sábio é sábio em e para si mesmo, e não precisa falar” (Foucault, 2017, p. 17). É a verdade ontológica.

Por fim, há um último modelo: o dizer-a-verdade do professor. Um dizer verdadeiro caracterizado pelo domínio da técnica, know-how, são "conhecimentos que tomam corpo numa prática e que implicam, para seu aprendizado, não apenas um conhecimento teórico" (Foucault, 2017, p. 23). Uma verdade baseada na tradição que deve ser transmitida. "Ele tem a obrigação de dizer o saber que possui e a verdade que conhece, porque esse saber e essa verdade estão ligados a toda uma tradicionalidade" (Foucault, 2017, p. 24). É domínio da tékhne.

Creio que poderia ser interessante procurar saber como essas quatro modalidades [...] se combinam nas diferentes culturas, sociedades ou civilizações, nos diferentes modos de discursividade, no que poderíamos chamar de "regimes de verdade" (Foucault, 2017, p. 27).

As características de cada um desses modelos podem se combinar e se articular de diversas maneiras. Por exemplo, ao comentar o que predominaria no tempo presente, o autor é taxativo em afirmar que: "vocês encontram a modalidade do dizer-a-verdade profético em um certo número de discursos políticos, de discursos revolucionários" (Foucault, 2017, p. 29). A “modalida- 
de tecnicista do dizer-a-verdade se organiza muito mais em torno da ciência do que no ensino" (Foucault, 2017, p. 29). Para o autor, a modalidade parresiasta seria justamente a que mais se enfraqueceu nas disposições do jogo da verdade. Marco aqui essa questão, a qual retomarei no final: a possível crise desses dizeres verdadeiros como resultado do enfraquecimento do dizer verdadeiro ético.

E, como se formulariam regimes de verdade a partir de tais modelos? Em O poder psiquiátrico (2012), o filósofo faz uma breve exposição sobre o que ele chama de uma história da verdade. Esclarece que, na sociedade ocidental, nos deparamos, grosso modo, com dois tipos de séries sobre a verdade, regimes que predominariam até os nossos dias.

A primeira matriz se assenta na organização do saber científico, para o qual a verdade está em toda parte, em todo lugar, ou seja, ela é plenamente alcançável, pois, "para a prática científica [...] sempre há verdade; a verdade está sempre presente em toda coisa ou sob toda coisa, a propósito de tudo e de qualquer coisa pode se colocar a questão da verdade" (Foucault, 2012, p. 302). Aqui, já podemos perceber que o modo de veridicção da técnica tem uma grande força.

Ainda sob essa perspectiva, a verdade habitaria tudo e qualquer coisa, por conseguinte, "não há ninguém que seja exclusivamente qualificado para dizer a verdade", como "não há ninguém tampouco que, de saída, seja desqualificado para dizer a verdade" (Foucault, 2012, p. 302).

O filósofo denomina essa série de "verdade conhecimento ou verdade demonstrativa". Antes de apresentar a outra série, ele nos deixa uma ironia nada sutil: essa verdade-conhecimento é segura, inquestionável, desde que "se disponha dos instrumentos necessários para descobri-la, as categorias necessárias para pensá-la e a linguagem adequada para formulá-la em proposições” (Foucault, 2012, p. 302), ou seja, para o autor, esse regime de verdade se elaborou como uma grande tecnologia de ação discursiva-demonstrativa sobre as demais.

Lembremos os argumentos do grupo Globo e como são evocados, em seu dizer verdadeiro, esses elementos sobre os quais fala o autor: "pode-se dizer que o jornalismo é o conjunto de atividades [instrumentos] que, seguindo certas regras e princípios [categorias], produz um primeiro conhecimento sobre fatos e pessoas [a linguagem jornalística]." (Organizações Globo divul- 
gam..., 2011). Nesse sentido, está claro que o jornal opera como um modelo de veridicção da técnica.

Foucault argumenta que, além dessa "verdade-conhecimento", há outro posicionamento sobre a verdade que foi eclipsado, colonizado pela primeira; uma verdade-acontecimento, que seria:

Uma verdade dispersa, descontínua, interrompida, que só falaria ou que só se produziria de tempo em tempo, onde bem entender, em certos lugares; uma verdade que não se produz em toda parte o tempo todo, nem para todo mundo; uma verdade que não nos espera, porque é uma verdade que tem seus instantes favoráveis, seus lugares propícios, seus agentes, seus portadores privilegiados. [...] Verdade que tem sua geografia, verdade que tem seu calendário ou, pelo menos, sua cronologia própria (Foucault, 2017, p. 303).

Essa verdade seria, portanto, uma verdade situada, dotada de mensageiros próprios autorizados a falar: "são os que pronunciaram as palavras requeridas ou consumaram os gestos rituais” (Foucault, 2017, p. 304). Ela não seria, portanto, uma verdade universal, para Foucault, e sim de uma verdade que se produz como acontecimento. Aqui, podemos identificar que o dizer-a-verdade profético exerce uma função bastante relevante. $\mathrm{O}$ autor sugere uma metáfora para distinguir essas duas séries de verdades: a segunda seria uma verdade "raio", que captura um lampejo, podemos dizer, em oposição à verdade "céu", constante e inabalável, da primeira perspectiva. Assim, teríamos uma verdade demonstrativa, total, universal. Aqui, estou chamando de "verdade verdadeira", em oposição a uma verdade fragmentada, temporal, dispersa; verdade acontecimento.

Foucault defende que, embora, a verdade-conhecimento tenha se construído como diferente, metódica e cirúrgica, em seu âmago, essa é também uma verdade ritual, e uma "certa modalidade de verdade". "Essa verdade-demonstração deriva na realidade da verdade-ritual, da verdade acontecimento, da verdade-estratégia, como a verdade-conhecimento no fundo não passa de uma região, de um aspecto [...] que adquiriu proporções gigantescas" (Foucault, 2017, p. 305).

Para ele, essas duas séries devem ser compreendidas dentro de um processo em que essas tecnologias de verdade, progressivamente, a partir do século XVIII, rivalizaram num jogo de forças do qual saiu vitoriosa a verdade- 
-conhecimento. Para o autor, essa vitória só foi possível porque, nesse regime, a verdade foi vinculada aos procedimentos políticos do inquérito e à própria sociedade capitalista ocidental.

O inquérito, o relatório, o testemunho de muitos, o cruzamento das informações, a circulação do saber, desde o centro de poder até seu ponto de chegada e seu retorno, todas as instâncias paralelas de verificação também, tudo isso constituiu progressivamente, pouco a pouco, ao longo de toda uma história, o instrumento de poder político e econômico que é o da sociedade industrial (Foucault, 2012, p. 315).

Para finalizar, o autor sugere que, no último estágio do avanço dessa série (regime) colonizadora, houve uma modificação em sua legitimação, não sobre a certeza da existência de tal série em todo lugar, mas sobre os sujeitos/peritos autorizados a dizerem-na, “dos filósofos, dos homens de ciência, dos intelectuais, dos professores, dos laboratórios" (Foucault, 2012, p. 315).

Após essa necessária exposição teórica sobre as ideias de Foucault, na qual procurei estabelecer a diferença entre modelos de veridicção e regimes de verdade, marco o aspecto referente à problemática da verdade no espaço público e a sua relação com a nova onda de negação e falseamento a que assistimos.

Tanto o jornalismo como a história se constituíram como campos do saber assentados no modelo de dizer-a-verdade técnico. Este, por sua vez, se apresenta como um dos grandes pilares dentro de um regime de verdade que Foucault nomeou de "verdade-conhecimento". É preciso ressaltar que um regime de verdade não se sustenta apenas em seus modelos de veridicção, ele precisa também se articular com as formas de governamentalidade e também com os modos de constituição do sujeito, através das práticas de si, elementos os quais, em virtude do espaço, não serão abordados aqui.

Nesse regime de verdade, diferentes compreensões sobre o que ela é, e como funciona em uma dada sociedade, podem ganhar corpo e apropriações diversas na cena pública. Como objetivo a ser alcançado, há uma dimensão profética da verdade que continua a operar, aferrada nas ideias de uma verdade "a ser revelada", "iluminadora do real”, algo que será descoberto. Destarte, a verdade verdadeira ainda se constitui como aspecto forte nessa distribuição do conhecimento. No circuito da informação voltada ao grande público, a 
compreensão dessa verdade é não apenas afirmada, mas apresentada como o principal produto vendido sob os mais variados formatos.

Onde, então, se situaria o problema do novo negacionismo nessa lógica? Defendo que, no espaço público, as principais disputas em torno da verdade que envolvem a negação e o falseamento dos conteúdos comunicacionais e científicos - se realizam dentro desse regime de verdade-conhecimento o qual, em sua matriz, não é rejeitado, percebendo-se, nele, uma movimentação sobre os modelos de veridicção que sustentam uma ideia geral do que seja a "verdade".

A compreensão sobre como se posicionam os modelos de veridicção nesse regime de verdade necessitaria de um esforço bem maior do que permite o espaço desse artigo. No entanto, aqui irei sugerir que, em nosso tempo, o enfraquecimento, ou a quase inexistência do dizer-a-verdade ético, como moderador fundamental nesses enquadramentos da verdade, pode ter se tornado uma questão-chave para entendermos o aumento negacionista. Numa sociedade instaurada na dispersão de vozes, enfraquecida em seus laços sociais, eclipsou-se - ou tem se anulado - o dizer-a-verdade parresiasta, aquele personagem capaz de estabelecer a relação franca como o outro e dizer-lhe a verdade sustentada num éthos.

Essas disputas entre o verdadeiro e o falso ganharam profundos enredamentos políticos, pois os sistemas democráticos contemporâneos também se sustentam nesses pilares. Se, num primeiro momento, a negação não parece ter surgido como um projeto pensado ou como uma estratégia na disposição desses lugares de enunciação, a experiência dos últimos anos tem demonstrado suas potencialidades corrosivas.

O enredamento negacionista a que assistimos é um movimento fragmentado que se espraia sobre os mais variados dizeres verdadeiros que sustentam a ciência, o jornalismo, a escola, a medicina, mas também a política e a justiça, para citarmos alguns objetos desses enfrentamentos. Portanto, há um arranjo no jogo de disposição entre verdadeiro e falso, negação e afirmação. É novamente Foucault quem nos ajuda a pensar tais elementos, ao chamar atenção para a necessidade de se pensar uma história política das veridições:

Trata-se mais de definir em sua pluralidade os modos de veridição, de procurar as forças de obrigação por meio das quais eles se aplicam e as esferas de objetos que eles trazem à tona, enfim, as relações, conexões e interferências estabelecidas entre eles (Foucault, 2018, p. 11). 
Neste tópico, procurei estabelecer o problema da negação, pela chave da compreensão sobre as formas de veridicção exercitadas no espaço público. Essa disputa nem sempre se dá respeitando o território e as regras projetadas por esses modos de veridicção, mas gira em torno da legitimidade do ato de dizer a verdade, mesmo que sejam utilizados os subterfúgios da negação e do falseamento para se erodirem a autoridade de fala dos sujeitos clássicos do conhecimento: o/a cientista, o/a professor/professora, o/a jornalista e o/a historiador/historiadora.

\section{MEMÓRIAS CONFLITANTES OU ESTRATÉGIAS NEGACIONISTAS? As ARMADILHAS DA NEGAÇÃo NA CENA MIDIÁTICA - O EXEMPLO DA DITADURA MILITAR}

Nesse ponto, pretendo estabelecer uma análise tomando por base os modos de veridicção e os regimes de verdade em Foucault, para pensar o exemplo concreto da negação da ditadura militar.

As disputas em torno das versões sobre a ditadura militar sempre foram um problema para nossa sociedade, mas é importante se sublinhar que a associação de uma parte dessas representações ao negacionismo só passou a ser realizada há bem pouco tempo. Antes, tais versões quase sempre foram aceitas como objetos de memórias divergentes. A partir de 2018, quando a relação entre as interpretações do episódio e o conceito de negação passou a ser repetidamente explicitada, os usos do conceito "negacionismo", relacionados à ditadura militar, tornaram-se mais frequente. Mas algumas menções já ensaiavam enfrentar a questão, a exemplo de 2014, às vésperas dos 50 anos do episódio, quando o filósofo Vladimir Safatle abordou diretamente a problemática no jornal Folha de S. Paulo:

Tais análises são dignas do puro e simples negacionismo. Pois será sempre negacionista toda historiografia que visa minimizar crimes contra a humanidade, servindo-se de leituras tortas para dirimir o ímpeto social por punição e justiça contra os que se serviram do Estado para impor um regime assentado na violência bruta e na eliminação de setores descontentes da população. (Safatle, 2014, grifamos)

O recado de Safatle é claramente direcionado ao historiador Marco Antonio Villa, que, naquele ano, lançara Ditadura à brasileira: 1964-1985, a de- 
mocracia golpeada à esquerda e à direita. No livro, Villa efetiva uma espécie de negacionismo à brasileira, ao defender a tese de que, dentro do "regime militar", apenas dez anos podem ser realmente considerados como uma ditadura, "o período de vigência do Ato Institucional n. ${ }^{\circ}$ 5, de 13 de dezembro de 1968 a 31 de dezembro de 1978" (Villa, 2014, p. 370). Por isso, na maior parte do livro, o termo usado para se referir ao período é "regime militar", e não ditadura, a qual, para o autor, havia sido branda, comparada às demais ditaduras do Cone Sul.

Caroline Bauer e Fernando Nicollazi, ao se debruçarem sobre o editorial "Golpe à brasileira", de autoria de Villa e publicado no jornal O Estado de São Paulo, afirmam: "sua escrita da história, assim como sua atuação midiática, são também formas de uso público e, portanto, uso político do passado [...] são combates pela memória" (Bauer e Nicollazi 2016, p. 831). Caroline Bauer (2018) argumenta que as versões negacionistas da ditadura militar ganharam força e reaparecem em 2013, "nas demandas de retorno dos militares ao poder, acrescidas de um posicionamento de hostilidade frente aos trabalhos em desenvolvimento da Comissão Nacional da Verdade" (Bauer, 2018, p. 198).

Outros historiadores, ao tratarem do tema da memória sobre o período, como Aarão Reis Filho (2004, p. 34), ressaltam que "o que importa, [...] é chamar atenção para os grandes traços dos embates que se travam [...] para como elaboraram a memória do que se passara" (Reis Filho, 2004).

Nessa linha, o historiador Rodrigo Patto Motta (2013, p. 63) chama atenção à dificuldade do trabalho com essas memórias divergentes, apontando para os riscos que corremos ao utilizá-las como fontes históricas que, embora fundamentais, "este território, em que se travam agudas batalhas de memória, configura verdadeiro campo minado para o pesquisador acadêmico, cuja função é (ou deveria ser) usar a memória como fonte [...]".

Ainda, segundo Rodrigo Patto, seria o trabalho técnico do historiador uma ferramenta eficaz para mediar e posicionar tais fontes e memória, ou mesmo narrativas advindas do campo jornalístico, em patamares mais seguros de interpretação, pois, para ele, "existem peculiaridades adquiridas na formação e na experiência de trabalho do historiador que o qualificam para oferecer contribuição peculiar ao estudo dos temas recentes" (Reis Filho, 2004, p. 63).

Não há dúvidas que nos deparamos com uma série de fraturas na construção desse passado recente e que é legítimo falarmos sobre um campo de 
memórias em disputa. Aleida Assmann nos adverte que houve uma intensificação do problema da memória nos últimos anos e, "enquanto certos tipos de memória se retraem (como a memória da aprendizagem, formativa e, com referência à Shoah, a memória experiencial) outras formas ganham claramente importância, como a das mídias e da política” (Assman, 2011, p. 20).

Com os avanços dessas disputas na cena pública, especialmente influenciadas pelos mais variados media, questiono se, ao colocarmos tais produções, ao estilo da desenvolvida por Marco Antonio Villa, no rol das disputas de memórias, não estamos minimizando os efeitos de uma argumentação que se demonstra claramente negacionista. Se não estamos correndo o risco de legitimar versões "abusivas" (Baets, 2013) do passado e da própria história, na medida em que versões deliberadamente produzidas para negar o passado passam a ser consideradas como meras versões divergentes deste passado.

Mateus Pereira (2015) chama atenção para o fato de que, nos últimos anos, pudemos assistir, mais do que a uma disputa de memória, ao recrudescimento dos discursos negacionistas e revisionistas, disseminados em uma espécie de rede da "negação" no espaço público através da internet; local promissor para uma verdadeira "guerra" de memórias "sobre a Ditadura Militar nas suas inter-relações entre o 'virtual', o 'atual' e o 'real”'. (Pereira, 2015, p. 869).

$\mathrm{O}$ autor nos faz pensar como é fundamental que refinemos nosso olhar para a diversidade de narrativas em nossa cena pública, e também para as maneiras como estas elaboram perspectivas que, muitas vezes, se sustentam em ideologias autoritárias, pois “a negação, em seu sentido ideológico, bem como o revisionismo, em seu sentido absoluto e relativo, está intimamente ligada àquilo que Ricoeur chama de abuso de memória e de esquecimento, em particular, de memória manipulada" (Pereira, 2015, p. 879).

Embora seja inequívoco que estamos lidando com uma série de memórias fragmentadas e dispersas sobre a ditadura militar, há um elemento específico que gostaria de destacar, e que nos coloca um desafio eloquente: como distinguir as legítimas configurações de memórias discordantes dos investimentos negacionistas postos em nossa cena pública? Como questiona Mateus Pereira, a partir da citação de Roberto Vecchi (2001, p. 87-88 apud Pereira, 2015, p. 870) “qual é a ética necessária para usar a memória sem cair nas armadilhas do revisionismo, numa palavra, como representar a barbárie, apesar de todas as aporias miméticas, para fundar a sua memória?”. 
Vejamos mais um exemplo:

A esquerda brasileira que se diz ter combatido pela liberdade, mente! Grande parte dos professores de história também mente porque eles são de esquerda.

[...] A ditadura acabou e a esquerda tinha as redações dos jornais os centros culturais e a universidades, e com o tempo foi aumentando e agora tem as escolas também, professores do ensino médio que ensinam que o José Genuíno lutava pela liberdade, o que é mentira.

[...] quem conhece um pouco de história sabe que os regimes de esquerda foram extremamente violentos, extremamente totalitários.

[...] O que combatentes da guerrilha do Brasil queriam: eles queriam destruir uma ditadura que representava os interesses americanos, porque eles queriam transformar o Brasil numa grande Cuba (Pondé, 2017, grifamos).

A fala acima, do filósofo Luiz Felipe Pondé, colunista do jornal Folha de São Paulo, faz parte de um episódio do programa "Guia Politicamente Incorreto de História do Brasil", dedicado à ditadura militar e, em especial, aborda o papel das esquerdas. O episódio compõe uma série de oito programas baseados na obra homônima do jornalista Leandro Narloch, produzida e distribuída pelo History - canal fechado, mas cujos produtos podem ser facilmente encontrados em canais do YouTube, e possuem centenas de milhares de visualizações.

$\mathrm{Na}$ fala, estão presentes arquétipos muito aproximados da comunicação do governo bolsonarista, mencionada anteriormente, mas, sobretudo, argumentos que circulam em abundância nas redes sociais, tais como a repetição do medo anticomunista como justificativa para o Golpe; a ditadura abrandada pela possibilidade de coisa pior, como a ditadura de esquerda; o mito do país se tornar uma grande Cuba.

Há ainda outro silogismo também bastante capilarizado em nossa sociedade para atacar a legitimidade dos professores de história. Logo na primeira intervenção escolhida como destaque para o teaser do programa, o filosofo é taxativo: "a esquerda brasileira mente", "a maioria dos professores de história do Brasil são de esquerda, portanto, a maioria dos professores de história mente" (Pondé, 2017).

Os elementos presentes na fala de Luiz Felipe Pondé são legitimados pelo lugar que ele ocupa como técnico; o filósofo que se pronuncia a partir de um dado modo de dizer-a-verdade. Sustenta-se, principalmente, pela dimensão 
política de aceitação desses argumentos nas redes de sujeitos que compartilham das mesmas ideias. Então, deve-se considerar que "nessa perspectiva, para se reprimir, silenciar, falsear ou esquecer é preciso contestar a realidade do que se passou durante a Ditadura Militar brasileira não necessariamente pela mentira, mas pela negação e também pelo revisionismo, que distorcem e justificam os crimes e o estado de exceção" (Pereira, 2015, p. 877).

As generalizações presentes em seu raciocínio, como, por exemplo, quando trata a esquerda como um bloco coeso, ou ainda, as justificativas da ditadura pelo perigo comunista, transitam em nossa cena pública desde os anos 60 , ou mesmo antes, mas, nos últimos anos, são acrescidas pela força das desqualificações dos professores de história e dos historiadores.

Nesse ponto, gostaria de ressaltar que, no caso da história, percebe-se não a sua negação como campo do conhecimento, mas sim, a negação da história produzida por determinados sujeitos. Essas estratégias de negação conseguem mobilizar aquilo que Estevão Rezende chama de um otimismo gnosiológico, "esse otimismo consiste no fato de afirmar-se que a verdade não apenas existe, como é alcançável" (Martins, 2011, p. 293). A permanência deste "otimismo gnosiológico" em nossa sociedade, que também se vincula ao regime de verdade-conhecimento, da qual nos fala Foucault (2012), pode ser utilizada como uma espécie de engenharia reversa pelas narrativas negacionistas.

As práticas de negação manipulam essa crença em uma verdade plenamente alcançável, exatamente para fazerem desmoronar todo um conjunto de conteúdos, o qual não satisfaz os desejos daqueles que as difundem. Assim, o argumento "da" verdadeira história torna-se um recurso poderoso para a negação do conhecimento histórico e, por sua vez, atua como uma poderosa arma política.

Na lógica dessa produção negacionista, um outro produto ganhou notoriedade, não pelos argumentos que apresenta, os quais continuam os mesmos que discuti até aqui, mas pelo formato oferecido através das novas mídias de compartilhamento. Falo do documentário 1964 - O Brasil entre armas e livros (2019), produzido pelo grupo empresarial Brasil Paralelo. Associado ao vídeo, o grupo lançou um artigo explicativo no qual realiza uma discussão sobre os temas tratados no documentário. Destaco alguns elementos para demonstrar como eles estão presentes nos três exemplos citados anteriormente: o telegra- 
ma do governo Bolsonaro, o livro de Marco Antonio Villa e a fala de Luiz Felipe Pondé no programa de televisão. Vejamos:

A Ditadura Militar no Brasil é um dos períodos mais deturpados de nossa história. [...] Entenda como foram os vinte anos de regime militar sem qualquer apologia aos erros cometidos, mas também sem ocultar a necessidade de uma intervenção que pudesse deter o comunismo.

[...] Seu conteúdo é fruto do estudo de dezenas de especialistas. Eles nos ajudaram a encontrar bibliografias e documentos que mostram a história do período em que os militares estavam no poder.

[...] Finalmente, começaremos a entender o vínculo entre a Guerra Fria e a verdadeira história da Ditadura Militar no Brasil. Já entendemos como o mundo estava dividido e como as revoluções socialistas eram um terror vermelho, amplamente difundido pela URSS.

Bandidos e terroristas, hoje venerados como heróis nacionais, sequestraram, torturaram e assassinaram inocentes em nome de seus ideais. Esta é uma verdade pouco noticiada nos anos seguintes pela imprensa e academia brasileira.

A vitória da revolução cubana em 59 intensificou as atividades comunistas na América Latina [...] (Redação Brasil Paralelo, 2020, grifamos).

Os elementos presentes no excerto acima reúnem um conjunto de teses que funcionam como uma grande arquitetura da negação desse episódio em nossa sociedade. Constata-se que está em movimento uma rede que se alimenta continuamente e se estruturou a partir de elementos antes dispersos, mas que hoje conseguem operar articulados em discursos os quais pretendem colocar em evidência outros sujeitos autorizados a "revelar" a verdade sobre 1964. Nos quatro registros mencionados, desenha-se a mesma disposição do raciocínio negacionista cuja base é a defesa de uma verdadeira história a ser revelada, a qual teria sido deturpada pela historiografia tradicional.

Todavia, os problemas em torno do negacionismo não decorrem somente de uma correlação de forças sobre os alcances do dizer-a-verdade em termos de uma disputa epistêmica. Na contemporaneidade, eles advêm também dos processos de difusão, alcance e apropriação de conteúdos produzidos fora dos lugares profissionais, mediados pela autoridade técnica; o dizer-a-verdade do professor, conforme nos propôs Foucault.

Minha sugestão é que, além da intencionalidade de manipulação do pas- 
sado dessas práticas negacionistas, estamos diante de uma relação enferma com esse passado (Ricoeur, 2007), tanto no que diz respeito à história, mas também à memória, submetidas a uma certa compulsão pela repetição de elementos há muito projetados em nossa cena pública.

Arquétipos são insistentemente acionados sempre que se apresentam momentos de crises e rupturas. É o caso do discurso anticomunista ${ }^{4}$, da aversão a Cuba e da idealização das forças armadas como justificativa salvacionista da nação, como mencionados anteriormente. Nesse sentido, ressalto as questões apontadas por Paul Ricoeur (2007) sobre os impedimentos da memória, ou sobre como nossa sociedade parece não ter conseguido realizar, de forma satisfatória, um trabalho de elaboração sobre esse acontecimento. O autor nos propõe refletir sobre a complexa relação entre memória e esquecimento, com a qual nos deparamos em sociedades que passaram por episódios traumáticos recentes.

Em suas reflexões sobre os abusos da memória, Paul Ricoeur enfrenta a problemática de pensar a memória a partir de três dimensões que se conectam pela chave do impedimento, quais sejam: a memória impedida, a memória manipulada e a memória exercida de maneira abusiva.

A partir de suas reflexões, podemos pensar a construção da memória sobre a ditadura no Brasil, nas duas primeiras chaves: impedimento e manipulação. Mas, há ainda outro aspecto em suas reflexões, que se conectam com esses dois elementos: o exercício de um esquecimento comandado como política de estado, o qual, de certa maneira, corroborou para que a memória sobre os 21 anos da ditadura militar não se consolidasse como memória viva para essa sociedade.

Em suas proposições, Ricoeur ressalta o trabalho de luto como fundamental para que um processo de rememoração possa se completar numa justa memória. A elaboração sobre o que é lembrado, de maneira que se rompa o ciclo da melancolia, o drama da repetição da perda, ou do episódio traumático. A partir das questões apresentadas por Freud, Ricoeur nos chama atenção para a necessidade de uma cura da memória, alcançada através de um trabalho de elaboração, denominado, em Freud, perlaboração.

Um esforço de compreensão que foi impedido de se concretizar ao não efetivarmos passos importantes para que esse passado fosse ressignificado de forma qualitativa no presente. Aspectos como uma justiça de transição, a in- 
vestigação e a punição de crimes perpetrados durante o período, o esclarecimento desses acontecimentos para parcelas mais amplas da população, ou mesmo, a própria escuta da voz das vítimas do período.

Entre as vítimas da ditadura, predomina a dificuldade de encerramento do luto, especialmente para os que tiveram parentes nunca encontrados. Já os torturados são atormentados pela impunidade de seus algozes e pela indiferença de uma expressiva parcela da sociedade. Deste modo, a postura de negação também pode ser associada à incapacidade de realização do trabalho de perlaboração sobre o acontecimento.

A compreensão sobre as leituras do nosso passado deve, necessariamente, ser submetida a uma dimensão ética, a um exercício que é o da relação viva com esse passado, que visa colocar sobre o presente uma necessidade de resposta a uma interpelação: como nos portamos hoje com aqueles que sucumbiram a esse processo? Por isso, como destaca Gagnebin (2020, p. 208):

Ricoeur insiste na relação entre memória do passado e exigência ética, opondo à "tirania da memória" e à febre comemorativa, [...] uma necessidade de pensar o trabalho de memória "sob a égide da ideia de justiça" (Ricoeur, 2007, p. 104). [...] Essa relação entre o passado, em particular entre os sofrimentos do passado e o presente, carrega a atividade memorial com o peso de uma tarefa que proíbe defini-la como uma figura ideal de objetividade, aquilo que a ciência histórica visa. [...] A memória, como força vital, nos permitiria prestar contas da dívida que temos com o passado - mas também de não permanecer nela eternamente presos [...].

A autora ressalta ainda que todas essas formas de impedimento de que nos fala o autor (memória impedida, memória manipulada e abusivamente acionada) são, em última instância, tentativas de impedimento da "escuta dessa interpelação e a resposta que lhe poderia ser dada no presente, dentro do presente e para o presente" (Gagnebin, 2020, p. 208). Tais elementos tornaram o ambiente brasileiro bastante receptivo às elaborações falsas e negacionistas sobre a ditadura militar. Mateus Pereira (2015, p. 880) afirma que "o trabalho de negação e/ou revisionismo é muito mais amplo do que a memória ou a perspectiva militar. Ainda assim, convém destacar que ele é fundado em uma retórica que idealiza, distorce, dissimula, justifica e milita por algum tipo de autoabsolvição [...]". 


\section{UM NOVO POSICIONAMENTO SOBRE OS MODOS DE VERIDICÇÃO?}

Gostaria de acrescentar um último aspecto a este cenário, que diz respeito à interferência das redes sociodigitais no posicionamento da verdade. Um dos aspectos problematizados aqui foi a preocupação das mídias tradicionais com a crescente perda de espaço ocasionada pela expansão de conteúdos na internet. Esta não é uma preocupação vã, pois, na segunda década do século XXI, houve a consolidação e o crescimento das redes sociodigitais na produção e na distribuição de conteúdos. O mesmo ocorre em relação à história, que vê seus consensos historiográficos recorrentemente confrontados por conteúdos das redes, mesmo que estes não tenham qualquer base sustentada em pesquisas ou protocolos de investigação.

Embora as redes de compartilhamento tenham trazido para cena pública a possibilidade de usuários produzirem seus próprios conteúdos, além de distribuírem-nos, há limites muito preocupantes nessas ações. No coração da web predominam grandes empresas que gerenciam gigantescos bancos de dados, economias nacionais, acervos ilimitados e, sobretudo, os dados pessoais de seus milhões de usuários, hoje o capital mais valioso dentro desse "liberalismo informacional" (Loveluck, 2018, p. 107).

Não há uma clareza sobre como esses dados têm sido utilizados por essas empresas e grupos políticos, com fins de intervenções em diversos processos sociais na contemporaneidade. Alguns gigantes da internet se especializaram no serviço de gestão algorítmica que controla aquilo que é visto nas redes e conseguem operar, quase numa dimensão microscópica, de sujeito a sujeito.

Destarte, o sociólogo Manuel Castells (2018) chama atenção para o fato de que, concomitantemente a esse processo de mudança comunicacional, vivenciamos a dissolução de vários paradigmas, além de uma crescente deslegitimação do sistema político tradicional. Isso explica, em parte, certa idealização do passado em várias postagens, como uma espécie de escapismo da crise que desconecta o passado do presente, este último, visto como um tempo pior. Em recente entrevista, ao se referir a essa nova onda negacionista a que assistimos no momento, o filósofo Bruno Latour chama atenção para a característica escapista dessas posturas de negação. Para ele, “[...] o negacionismo não é apenas uma questão cognitiva [...] trata-se de uma decisão já muito antiga, que chamo de escapismo" (Latour, 2020, p. 3).

As posturas de escapismo e negação passaram a ser compartilhadas nos 
ambientes digitais, ganhando nova roupagem, mas preservando elementos reacionários e bastante reativos em suas formulações. Essa configuração se coaduna com a distribuição da informação que agora se situa também no espaço reticular e fragmentado da horizontalidade das redes. Castells (2018) afirma que isso produziu uma espécie de "esquizofrenia estrutural", que colocaria o sujeito entre a Rede e o Ser.

O autor destaca ainda que esse novo sistema de comunicação se difunde através de um complexo processo de descentralização da informação, em oposição aos sistemas que antes concentravam enormes audiências em seus canais, como a televisão. Estaríamos vivenciando a era de uma cultura da virtualidade real, "um sistema em que a própria realidade (ou seja, a experiência simbólica/ material das pessoas) é inteiramente captada, totalmente imersa em uma composição de imagens virtuais" (Castells, 2018 p. 455). Nesse ambiente, a rede funciona como o grande mobilizador de posicionamentos e condutas capazes de agenciar afetos e ações. Segundo Wainberg (2018, p. 155), em diálogo com outros autores:

As redes sociais são encontros de pessoas que pensam e sentem de certa forma (Thelwall et. al, 2009) [sic]. Umas se animam de outras (Bakshy et. al., 2012) num círculo relativamente fechado, impedindo que fatos desconfortáveis lhes cheguem aos sentidos. Com a homofilia cria-se uma forte barreira às mensagens dissidentes. Cercamo-nos de pessoas parecidas conosco e, assim, fortalecemos nosso espírito com o espírito de quem não nos ameaça [...].

A interferência das redes sobre os modos de veridicção ocorre mais pela força quase ilimitada de seu poder de mobilização e pelo gigantesco volume de informação que são capazes de produzir, simultaneamente, do que propriamente pela novidade dos seus conteúdos. Deste modo, "além de difundidas em grande volume, as mensagens da máquina de propaganda [das redes] provêm de diferentes canais, o que também gera credibilidade" (Roque; Bruno, 2018).

Através dessa poderosa forma de organização que se sustenta, sobretudo, na mobilização de afetos, nos deparamos com um desafio real para a validação e a estabilização das formas tradicionais de dizer-a-verdade, exatamente porque o conteúdo fraudulento ou negacionista não se presta à crítica ou à validação de suas proposições fora do circuito no qual se desenvolve. "Ou seja, as pessoas tendem a recusar os fatos que contrariam suas teses. Elas preferem acolher de 
braços abertos ponderações conspiratórias, falsas e por vezes absurdas, desde que elas venham ao encontro de seus valores" (Wainberg, 2018, p. 155).

As pesquisadoras Tatiana Roque e Fernanda Bruno (2018), ao se debruçarem sobre o papel das redes sociodigitais nas eleições presidenciais de 2018, sugerem que a organização desses veículos cria verdadeiros ecossistemas em torno de personagens e ideias que se tornam universos quase intransponíveis para outros argumentos e informações.

É fato que as fakes tiveram um papel importante na eleição, mas não necessariamente porque as pessoas acreditaram ingenuamente em notícias produzidas pelo aparato de campanha do candidato. A confiança gerada pelas técnicas de comunicação de Bolsonaro cria um ambiente de credibilidade que favorece a circulação de mensagens com conteúdo que confirme crenças e valores prévios, sejam eles verdadeiros ou falsos (Roque; Bruno, 2018).

Deste modo, é preciso que consideremos que o avanço desse novo negacionismo se sustenta e se alimenta, em grande medida, por essa engenharia de distribuição de conteúdos cuja "estratégia aprimora um pressuposto da segmentação da propaganda: pessoas que repassam mensagens para seus grupos de afinidade possuem um papel estratégico, pois são fontes de confiança” (Roque; Bruno, 2018).

Ao longo desse artigo, apresentei algumas falas de personagens que se vincularam por uma mesma linha argumentativa de negação da ditadura militar. Eles colocam em ação um conjunto de argumentos que intentam produzir uma versão sobre esse episódio claramente pautada na amenização, na manipulação ou no desprezo pelas fontes que dizem o contrário de suas proposições. Argumentos que são colocados em movimento numa eficaz rede de distribuição que envolve vários sujeitos, produtos e linguagens, que se capilarizam em nossa sociedade pelas redes sociais. Essas se apresentam como o principal canal para difusão negacionista em nosso tempo, e, a partir de seus vários modos de atuação, têm colocado em xeque os modos de veridicção com os quais lidamos até aqui.

\section{Algumas CONSIDERaÇões Finais}

Neste artigo, procurei apontar alguns caminhos para compreendermos a profusão negacionista em nosso tempo, em sua manifestação na cena pública. 
Meu principal argumento foi o de que, para compreendermos a empreitada da negação no tempo presente, é preciso realizarmos um esforço de compreensão sobre os modos de veridicção que operam em nossos dias. Compreender como os vários modelos de dizer-a-verdade se organizam no espaço público nos ajudará a entender o que se nega, e porque se nega.

Nesta empreitada, parti das questões pontuadas sobre a verdade em Foucault $(2012,2017,2018)$ e da consideração de que, em nosso tempo, nos deparamos com modelos de verdade que se sustentam desde a antiguidade, com variações e adaptações que são mobilizadas em grandes regimes de verdade que predominam em determinadas épocas. Foucault pondera que, desde o iluminismo, nos encontramos sob a ordenação de uma grande série da verdade, denominada por ele como verdade-conhecimento, ou demonstrativa.

Tal regime posicionou a verdade com a predominância de alguns modos de veridicção, e aqui sugeriu que o modo de dizer-a-verdade da tékhne - do saber técnico-científico - se sobrepôs em relação aos demais, embora os outros não tenham deixado de atuar em alguma medida. Nesse modelo, destaquei dois campos que estão bem próximos: o jornalismo e a história, e como ambos sofreram reiteradas investidas negacionistas em nosso tempo.

Nesse processo, tomei como exemplo de conteúdo negado o caso da ditadura militar brasileira, objeto de intensas disputas em nossa sociedade. Problematizei a compreensão de que assistimos, ao longo dos anos, a uma disputa de memórias divergentes sobre o episódio, sugerindo que, mais do que o jogo de memórias divergentes, deixamos prosperar posicionamentos negacionistas.

Isto posto, o investimento massivo na desconfiança, na falsificação e na negação tem colocado em xeque os próprios dizeres verdadeiros tradicionais, pela avassaladora produção de conteúdos a que assistimos através das redes sociodigitais. A ideia de uma verdade total, inquestionável, verdade céu, como afirma Foucault, não é negada. Há, pelo contrário, um uso claro de sua possibilidade em todos os discursos negacionistas, mas investe-se no enfraquecimento contínuo desses lugares tradicionais de dizer-a-verdade. Essa onda negacionista pode indicar uma crise na matriz dessa verdade-conhecimento que enfrenta os limites de seu poder. Nesse contexto, a ideia de negação pode ser uma fratura não apenas na constituição desses vários modelos de veridicção, mas na ordenação da sociedade democrática que se erigiu sobre ela.

Os recentes casos de emergências reacionárias em vários países e a desle- 
gitimação acelerada dos lugares tradicionais que se sustentam num dado posicionamento da verdade, assentado no conhecimento e na informação, podem indicar elementos dessa crise. Um aspecto que tem sido fundamental nesses novos posicionamentos é a consolidação das redes sociodigitais e a produção de conteúdos deliberadamente feitos para manipular.

Ao final, retomo o que considero a questão mais desafiadora colocada ao nosso tempo. Ao questionar a si próprio sobre qual modelo de verdade predominaria a partir da época moderna/contemporânea, Foucault (2017, p. 29) afirma supor que: "a modalidade parresiástica, creio que justamente ela, como tal, desapareceu e não a encontramos mais, a não ser enxertada e apoiando-se numa das três modalidades".

O autor nos apresenta essa impressão em meados dos anos de 1980, bem antes de nos depararmos com a consolidação da internet e das redes sociodigitais. Lembremos que o exercício do dizer-a-verdade parresiástico era a coragem da verdade; a função de mediação ética do dizer verdadeiro que se realiza num jogo de aceitação entre aquele que pode dizer a verdade e o seu interlocutor, capaz de ouvi-la, por mais desagradável que ela possa ser. A verdade, portanto, que convive e aceita mesmo quando o saber pode se tornar pesado, mas que é capaz de se repensar. É exatamente a falta dessa mediação ética a que assistimos no universo de distribuição da verdade em nossa cena pública. É por sua falta que, talvez, podemos pensar o desequilíbrio nos posicionamentos sobre a verdade em nosso tempo e, assim, encontrar uma chave de compreensão para o avanço negacionista.

\section{REFERÊNCIAS}

ASSMANN, Aleida. Espaços da recordação: formas e transformações da memória cultural. Campinas: Unicamp, 2011.

BAETS, Antoon de. Uma teoria do abuso na História. Revista Brasileira de História. São Paulo, v. 33, n. 65, pp. 17-60, 2013.

BAKSHY, Eytan et al. The Role of Social Networks in Information Diffusion. In: CONFERENCE ON WORLD WIDE WEB, 21, 2012. Proceedings of the $21^{\text {st }}$ International Conference on World Wide Web. ACM, 2012. pp. 519-528.

BAUER, Caroline Silveira, NICOLAZZI, Fernando Felizardo. O historiador e o falsário: Usos públicos do passado e alguns marcos da cultura histórica contemporânea. Varia Historia, Belo Horizonte, vol. 32, n. 60, pp. 807-835, 2016. 
BAUER, Caroline. Qual o papel da história pública frente ao revisionismo histórico? In: MAUAD, Ana Maria; SANTHIAGO, Ricardo; BORGES, Viviane Trindade (Orgs.). Que história pública queremos?/What Public History Do We Want? São Paulo: Letra e Voz, 2018.

BORGES, Pedro; SIMÕES, Nataly; FIORAVATTI, Gustavo. Fundação Palmares censura biografias de lideranças negras históricas em seu site. 15 jun. 2020. Disponível em: https://www1.folha.uol.com.br/ilustrada/2020/06/fundacao-palmares-censura-biografias-de-liderancas-negras-historicas-em-seu-site.shtml. Acesso em: 3 dez. 2020.

CASTRO, Edgardo. Vocabulário de Foucault: um percurso pelos seus temas, conceitos e autores. Tradução de Ingrid Müller Xavier. 2a . Ed. Belo Horizonte: Autêntica, 2016.

CASTELLS, Manuel. A sociedade em rede. São Paulo: Paz e Terra, 2018.

DALCASTAGNE, Regina; VECCHI Roberto. Dossiê Literatura e Ditadura: Apresentação. Estudos de literatura brasileira contemporânea, n. 43, p. 11-12, 2014.

FOUCAULT, Michel. O poder psiquiátrico. São Paulo: Martins Fontes, 2012.

FOUCAULT, Michel. A coragem da verdade. São Paulo: Martins Fontes, 2017.

FOUCAULT, Michel. Malfazer, dizer verdadeiro. São Paulo: Martins Fontes, 2018.

GAGNEBIN, Jeanne Marie. Os impedimentos da memória. Estudos Avançados, Rio de Janeiro, v. 34, n. 98, pp. 201-218, 2020.

LATOUR, Bruno. Entrevista com Bruno Latour por Alyne Costa e Tatina Roque. Edições n-1.2020, p. 3. Disponível em: https://www.n-1edicoes.org/textos/127. Acesso em: 1 fev. 2021.

LOVELUCK, Benjamin. Redes, Liberdades e Controle: uma genealogia política da internet. Petrópolis: Vozes, 2018.

MARTINS, Estevão de Rezende. Tempo e Verdade. Proposta de critério para um conhecimento histórico confiável. In: SALOMON, Marlon (Org.). História, verdade e tempo. Chapecó, S.C.: Argos, 2011. pp. 291-322.

MENEGAT, Rodrigo. Bolsonaro mencionou a ditadura em 1/4 de seus discursos como deputado. 30 mar. 2019. Disponível em: https://www.estadao.com.br/infograficos/ politica,bolsonaro-mencionou-a-ditadura-em-14-de-seus-discursos-como-deputado,982285. Acesso em: 10 jan. 2021.

MOTTA, Rodrigo Patto Sá. Em guarda contra o perigo vermelho: o anticomunismo no Brasil (1917-1964). São Paulo: Perspectiva, 2002.

MOTTA, Rodrigo Patto Sá. História, Memória e as disputas pela representação do passado recente. Patrimônio e memória, São Paulo: Unesp, v. 9, n. 1, pp. 56-70, 2013.

ORGANIZAÇÕES GLOBO DIVULGAM documento com princípios editoriais, 6 ago. 2011; (4 min. 23 seg.); son.; color. Disponível em: https://www.youtube.com/ watch?v=sBbtZMwUlto. Acesso em: 4 jan. 2021. 
PEREIRA, Mateus Henrique de Faria. Nova direita? Guerras de memória em tempos de Comissão da Verdade (2012-2014). Varia Historia, Belo Horizonte, v. 31, n. 57 pp. 863-902, 2015.

PONDÉ, Luiz Felipe. Ditadura Militar no Brasil (1964-1985) - Guia Politicamente Incorreto da História do Brasil. 2017; (48 min. 53 seg.); son.; color. Disponível em: https://www.youtube.com/watch?v=pgXvp2akQ1Y\&t=6s. Acesso em: 15 dez. 2020. REIS FILHO, Daniel Aarão. Ditadura e sociedade: as reconstruções da memória. In: REIS FILHO, Aarão Daniel; RIDENTE, Marcelo; MOTTA, Rodrigo Patto Sá (Orgs.). O golpe e a ditadura militar 40 anos depois (1964-2004). São Paulo: Edusc, 2004. pp. 29-40.

REUTERS INSTITUTE: Digital News Report. Disponível em: https://www.digitalnewsreport.org/. Acesso em: 1 dez. 2020.

REUTERS INSTITUTE: Digital News Report. 2017. Disponível em: https://www.digitalnewsreport.org/survey/2017/. Acesso em: 19 abr. 2021.

REUTERS INSTITUTE: Digital News Report. 2019. Disponível em: https://www.digitalnewsreport.org/survey/2019/. Acesso em: 19 abr. 2021.

RICOEUR, Paul. A Memória, a história, o esquecimento. São Paulo: Unicamp, 2007.

ROQUE, Tatiana; BRUNO, Fernanda. Fenômeno da pós-verdade transforma os consensos já estabelecidos. 18 nov. 2018. Disponível em: https://www1.folha.uol.com. br/ilustrissima/2018/11/fenomeno-da-pos-verdade-transforma-os-consensos-ja-estabelecidos.shtml. Acesso em: 1 dez. 2020.

SAFATLE. Vladimir. Negacionismo. 18 mar. 2014. Disponível em: https://www1.folha. uol.com.br/paywall/login.shtml?https://www1.folha.uol.com.br/colunas/ vladimirsafatle/2014/03/1426964-negacionismo.shtml. Acesso em: 1 dez. 2020.

REDAÇÃO BRASIL PARALELO. Ditadura Militar no Brasil ou Regime Militar? Entenda definitivamente como foi o Golpe de 64.17 nov. 2020. Disponível em: https:// conteudo.brasilparalelo.com.br/historia/ditadura-militar-no-brasil/. Acesso em: 10 jan. 2021.

SENRA, Ricardo. Brasil diz à ONU que não houve golpe em 64 e que governos militares afastaram ameaça comunista e terrorista. 4 abr. 2019. Disponível em: https://www. bbc.com/portuguese/brasil-47818978. Acesso em: 10 jan. 2020.

THELWALL, Mike. Emotion homophily in social network site messages. First Monday, v. 15, n. 4-5, 2010.

VECCHI, Roberto. Barbárie e representação. In: PESAVENTO, Sandra Jatahy (Org.). Fronteiras do milênio. Porto Alegre: Editora da UFRGS, 2001. pp. 71-94.

VILLA, Marco Antonio. Ditadura à brasileira: 1964-1985, a democracia golpeada à esquerda e à direita. São Paulo: Leya, 2014.

WAINBERG, Jacques Alkalai. Mensagens fakes, as emoções coletivas e as teorias conspiratórias. Galáxia, São Paulo, n. 39, pp. 150-164, 2018. 


\section{NOTAS}

${ }^{1}$ Este artigo faz parte de pesquisa financiada pelo CNPQ através do edital de Produtividade.

${ }^{2}$ Recentemente, o presidente da fundação Palmares mandou retirar uma lista de personalidades negras da instituição, bem como reiteradamente tem feito ataques aos aspectos da história afro-brasileira, negando o racismo, censurando biografias de personalidades negras, assim como outros acontecimentos históricos envolvendo o tema. Cf. Borges; Simões; Fioravatti, 2020.

${ }^{3}$ Conforme Edgardo Castro, a parresía, em Foucault, "constitui uma das técnicas fundamentais das práticas de si mesmo na Antiguidade. No vocabulário do cuidado de si, 'parresía' é um termo técnico. [...] Falar com parresía, isto é, com liberdade da palavra, consiste em dizer ao enfermo as verdades da natureza que podem mudar o modo de ser do sujeito doente. Em segundo lugar, no contexto mais amplo, [...] refere-se tanto à atitude moral, ao éthos, do mestre, do diretor de consciência, quanto à técnica necessária para transmitir discursos verdadeiros" (Castro, 2016, p. 316-317).

${ }^{4}$ Sobre esse tema, a obra do historiador Rodrigo Patto continua sendo uma referência fundamental (cf. Patto, 2002). 